\title{
Healthy Eating and Active Lifestyle After Bowel Cancer (HEAL ABC): feasibility randomised controlled trial protocol
}

\author{
Jana Sremanakova ${ }^{1,2^{*}}$ (D) Anne Marie Sowerbutts ${ }^{1,2}$, Chris Todd ${ }^{1,2,3,4}$, Richard Cooke ${ }^{5}$ and Sorrel Burden ${ }^{1,2,4,6}$
}

\begin{abstract}
Background: Targeting modifiable lifestyle factors including diet and physical activity represents a potentially costeffective strategy that could support a growing population of colorectal cancer survivors and improve their health outcomes. Currently, effective, evidence-based interventions and resources helping people after bowel cancer to adopt new lifestyle habits are lacking. The aim of this trial is to test the Healthy Eating and Active Lifestyle After Bowel Cancer (HEAL-ABC) intervention to inform a future definitive randomised controlled trial.

Methods/design: This is a feasibility randomised controlled trial. A total of 72 survivors who have completed surgery and all anticancer treatments will be recruited. The intervention group will receive HEAL-ABC resources based on behaviour change theory combined with supportive telephone calls informed by motivational interviewing every 2 weeks during the 3-month intervention, and once a month for 6 months to follow-up. Participants in the control group will follow usual care and have access to resources available in the public domain. The study is testing feasibility of the intervention including adherence and ability to collect data on anthropometry, body composition, diet, physical activity, behaviour change, quality of life, blood markers, contact with healthcare services, morbidities and overall survival.
\end{abstract}

Discussion: The proposed study will add to the evidence base by addressing an area where there is a paucity of data. This study on lifestyle interventions for people after colorectal cancer follows the Medical Research Council guidance on evaluating complex interventions in clinical practice. It focuses on people living after treatment for colorectal cancer and targets an important research area identified by cancer survivors as a research priority reported by the National Cancer Institute and James Lind Alliance UK.

Trial registration: ClinicalTrials.gov NCT04227353 approved on the 13th of January 2020

Keywords: Colorectal, Cancer, Diet, Physical activity, Behaviour change, Survivorship

\section{Background}

Over recent decades, the number of people living with and beyond cancer has continued to rise worldwide. Current survival rates are associated with increased cancer incidence reaching 18 million new cases in 2018 [1],

\footnotetext{
* Correspondence: jana.sremanakova@manchester.ac.uk

${ }^{1}$ School of Health Sciences, University of Manchester, Oxford Road,

Manchester M13 9PL, UK

${ }^{2}$ Manchester Academic Health Science Centre, Manchester, UK

Full list of author information is available at the end of the article
}

ageing of the population [2] and advances in early cancer detection and treatment [3]. Several definitions of cancer survivorship have been proposed. One approach in research and within the medical community defines a person who has survived cancer as "living with and beyond cancer" [4].

There is mounting evidence that links lifestyle choices regarding diet and physical activity to primary cancer risk [5]. Likewise, large cohort studies have shown that

C C The Author(s). 2020 Open Access This article is licensed under a Creative Commons Attribution 4.0 International License, which permits use, sharing, adaptation, distribution and reproduction in any medium or format, as long as you give appropriate credit to the original author(s) and the source, provide a link to the Creative Commons licence, and indicate if changes were made. The images or other third party material in this article are included in the article's Creative Commons licence, unless indicated otherwise in a credit line to the material. If material is not included in the article's Creative Commons licence and your intended use is not permitted by statutory regulation or exceeds the permitted use, you will need to obtain permission directly from the copyright holder. To view a copy of this licence, visit http://creativecommons.org/licenses/by/4.0/ The Creative Commons Public Domain Dedication waiver (http://creativecommons.org/publicdomain/zero/1.0/) applies to the data made available in this article, unless otherwise stated in a credit line to the data. 
people who have survived cancer and followed healthy eating and active lifestyles can improve their survival rate [6]. It is therefore hypothesised that adherence to healthy diet and physical activity in people who have completed cancer treatment may reduce cancer risk, recurrences, comorbidities, new cancers, cardiovascular diseases and diabetes and improve overall survival rates [7]. However, there is insufficient evidence from randomised controlled trials (RCTs) to support this hypothesis. This has been highlighted in a systematic review on dietary interventions in adult cancer survivors, which revealed an uneven distribution of research across cancer sites [8].

Currently, evidence in cancer survivorship is centred predominantly on breast cancer studies $[8,9]$. There is a paucity of evidence for colorectal, gynaecological and prostate cancer. The global burden of colorectal cancer (CRC) is expected to increase by $60 \%$, which is more than 2.2 million new cases, by 2030 [10]. In England and Wales, almost six out of every ten people diagnosed with CRC survive their disease for 10 years or more [11]. However, survival is often affected by a number of physical and psychological problems including comorbidities [12], side effects from treatment including neuropathy, bowel disturbances [13], weight changes [14], cancer recurrences [15] or new cancer diagnosis [16] and surgical procedures can leave a proportion of patients with stoma. All these factors have a substantial impact on survivors' quality of life $[17,18]$. Helping people after cancer to follow a healthier lifestyle is a low-cost strategy that has the potential to mitigate health complications people may face after their treatment. To date, evidence indicates limited success at initiating long-term lifestyle changes in people living after cancer $[8,19]$ and effective evidence-based approaches to help people make substantial lifestyle changes after CRC are lacking.

Difficulties in identifying an effective lifestyle intervention may be influenced by the variety of interventions that have been tested and also by limitations in resources allocated to the development of an appropriate intervention. Dietary interventions are complex; however, there is guidance available from the UK Medical Research Council (MRC) on the development and evaluation of complex interventions in healthcare [20]. This guidance suggests piloting and feasibility testing to enhance the development and integration of complex interventions into healthcare. It also suggests involvement of participants in intervention development and conducting qualitative work to test acceptability, barriers and facilitators to adherence and uptake. There are diet and lifestyle interventions that have been developed incorporating some of these points to a high standard for people after breast cancer [21-23]; however, high-quality interventions for people after CRC are currently absent.
The proposed study aims to build on the current knowledge base by following MRC Guidance [20]. Prior to the protocol development, people after CRC were asked about their views and experiences of eating after a cancer diagnosis and their motivation for change [18] along with their preferences regarding delivery of lifestyle information [24]. This was combined with the development of an intervention resources which involved work with CRC survivors' and healthcare professionals [25]. Behaviour change theory was integrated throughout the resource [26].

The purpose of this study is to evaluate the feasibility of conducting a fully powered trial for a Healthy Eating and Active Lifestyle After Bowel Cancer (HEAL ABC) intervention versus usual care.

\section{Methods/design}

This is a feasibility parallel group RCT using 1:1 randomisation. The study follows CONSORT guidelines for reporting a pilot or feasibility trial [27] and follows the Standard Protocol Items: Recommendations for Interventional Trials (SPIRIT) [28]. Version 6 of the protocol has been finalised on 7th of January 2020.

\section{Eligibility and exclusion}

Participants will be included in the trial if they are over 18 years old, more than 12 weeks post-surgery and have completed all active anti-cancer treatments (surgery, radiotherapy or chemotherapy). Detailed inclusion and exclusion criteria are presented in Table 1.

\section{Recruitment and consent}

Participants will be recruited from outpatient CRC surveillance clinics in Great Manchester (Fig. 1). In the hospitals, appropriate participants will be identified from clinical records and screened by clinic staff. A record of people approached and individuals that express an interest will be kept. A patient information sheet and researcher contact details will be provided to facilitate follow up of potentially interested participants. The COVID-19 pandemic in UK in 2020 may preclude using this face to face approach, in which case an alternative non-face to face method of recruitment will be adopted. Participants who are interested in taking part will be consented, randomised and allocated to one of two trial arms. Baseline data will be collected following randomisation to the control or intervention arms.

\section{Intervention}

The intervention group will follow the HEAL ABC programme involving a written resource (Fig. 2) combined with supportive telephone calls every 2 weeks during the intervention and once a month during the follow-up period. 
Table 1 Inclusion and exclusion criteria

\begin{tabular}{ll}
\hline Inclusion criteria & Exclusion criteria \\
\hline Adults, age $\geq 18$ & Age $<18$ \\
$\begin{array}{l}\text { Minimum } 12 \text { weeks post-surgery and/or active treatment } \\
\text { Completed all active anti-cancer treatments, including surgery, } \\
\text { radiotherapy or chemotherapy }\end{array}$ & Less than 12 weeks post-surgery or active treatment \\
No serious health complications & $\begin{array}{l}\text { Short bowel syndrome, Crohn's disease, ulcerative colitis, diverticulitis or jejunostomy, } \\
\text { previous stroke, congested cardiac failure or oedema, hepatic or renal failure }\end{array}$ \\
No specific dietary requirements & On any therapeutic diets, multiple food intolerances or allergies \\
Body Mass Index $\geq 20 \mathrm{~kg} / \mathrm{m}^{2}$ & Body Mass Index $<20 \mathrm{~kg} / \mathrm{m}^{2}$ \\
Unintentional weight loss $\leq 5 \%$ in the previous 3-6 months & Unintentional weight loss $>5 \%$ in the previous 3-6 months \\
Following $<4$ of the WCRF/AICR recommendations & Already following $\geq 4 \mathrm{WCRF} / \mathrm{AICR}$ recommendations \\
Ability to work with computer, smart phone or tablet & Inability to work with computer, smart phone or tablet \\
Ability to give informed consent & Inability to give informed consent \\
\hline
\end{tabular}

WCRF/AICR World cancer Research Fund and American Institute of Cancer Research

\section{HEAL ABC resources}

Participants allocated to the intervention will be encouraged to follow HEAL ABC resources (Fig. 3) in order to make a healthy eating and active lifestyle changes. Development of the HEAL ABC resources and qualitative evaluation from people after bowel cancer, healthcare professionals and researchers is described elsewhere [25].

Resources are based on the World Cancer Research Fund and American Institute of Cancer Research (WCRF/ AICR) guidelines on diet and physical activity for cancer prevention [7, 29]. Suggestions for physical activity and exercise are based on a strategy, which integrates physical activity into everyday life tasks, that has been shown to be more effective than structured exercise programmes in exercise facilities [30, 31]. Resources have incorporated recommendations from the Health Action Process Approach (HAPA) [26], a behaviour change theory.

\section{Behaviour change}

The HEAL ABC resources consist of 12 booklets and additional supportive sheets. The order of the booklets is not specified. Participants start with an assessment booklet and review their current diet and physical activity level. Following the assessment, participants will be assigned their first booklet based on the one they perceive to be the easiest for setting an incremental goal and achieving it [32]. Meaning participants start with the booklet of the highest self-efficacy and after they achieve a successful behaviour change, they can move more confidently to the next booklet. During the follow-up period, participants will use the follow up booklet, which helps them to continue with changes they have made and encourage them to set new goals (Table 2).

The HAPA model for behaviour change was selected for the resources as it has been developed directly to target health-related behaviours [26]. This theory takes into consideration behavioural aspects that support the formation of intention to change to post-intentional phase of behaviour maintenance and recovery. The HAPA constructs have been mapped in HEAL ABC booklets, incorporated into tasks and activities within the booklets to support intention, action, maintenance and the recovery self-efficacy of study participants (Table 3).

\section{Telephone calls during 3-month and 6-month periods}

Participants in the intervention group will receive a telephone call every 2 weeks during the intervention period and once a month during the follow-up period. Calls aim to support participants' use of HEAL ABC resources to facilitate behaviour change by reviewing participants' goals for desired behaviour change. The structure of the telephone calls will be informed by motivational interviewing [33], with the interviewer trained in motivation interviewing technique. The interviewer will explore participant's own ability to identify the most appropriate plan for their action and explore their strengths and capabilities to change. Guidance will be provided to participants in order to set new goals if satisfactory changes were initiated. The telephone calls will be audio-recorded with an encrypted voice recorder to enable the monitoring and reviewing of the calls and evaluation of the intervention fidelity [34].

\section{Control (HEALTH group)}

Participants allocated to the control group will be referred to the healthy lifestyle recommendations available at the World Cancer Research Fund, Bowel Cancer UK and UK government websites. No additional support or telephone calls will be provided.

\section{Assessment and outcomes}

Both intervention and control group are assessed at baseline, 3- and 6-month data collection points. The schedule of enrolment, interventions and assessments is presented in Table 4. 
Potential participants identification.

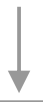

Approached participants are informed about the trial. If they are interested they will be provided participant information sheet.
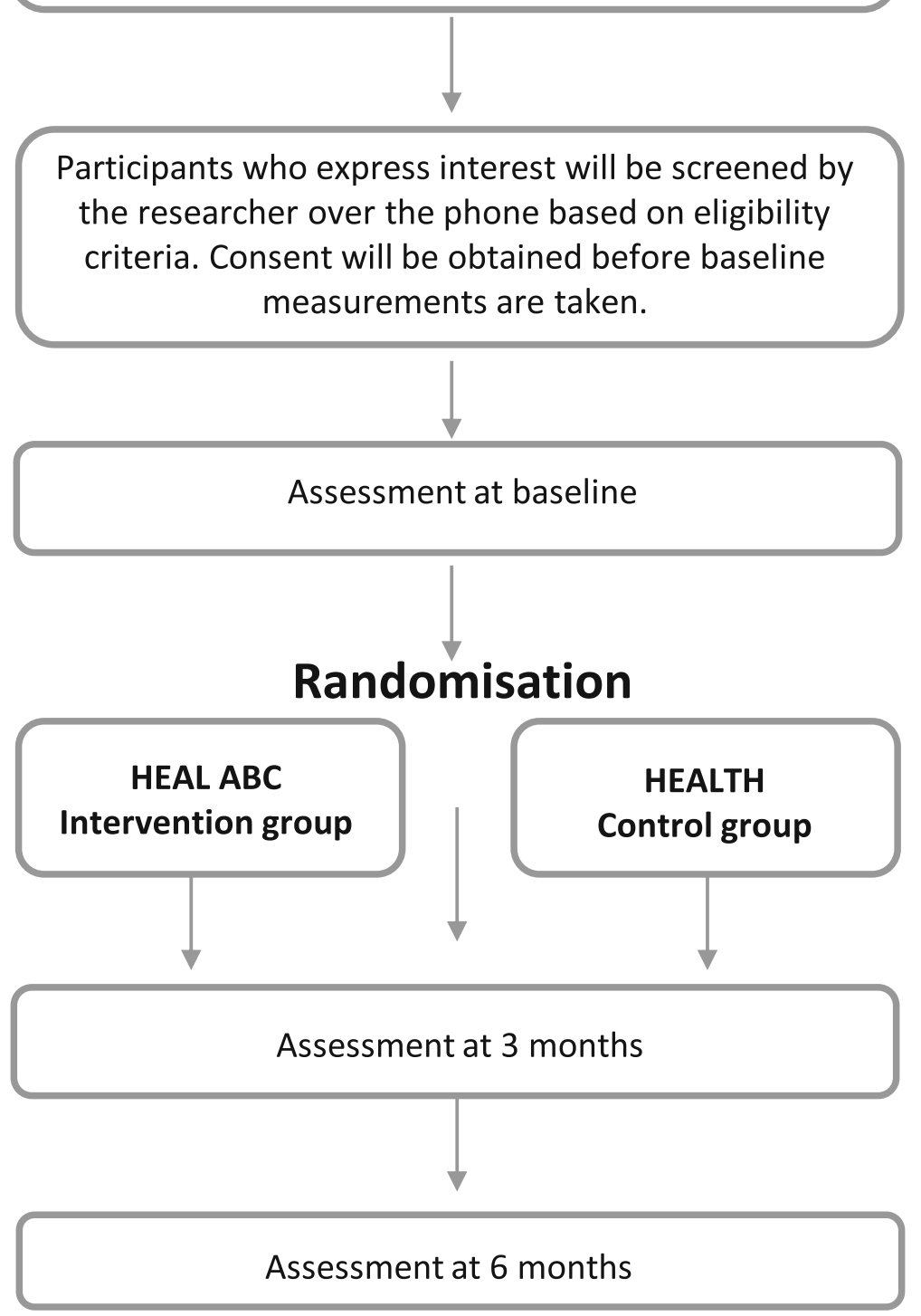

Fig. 1 Study flow diagram

\section{Baseline assessment}

At baseline, details of patients' characteristics will be collected using a sociodemographic questionnaire (see Additional file 1). Patient medical records will be used to collect information on cancer staging using the
Classification of Malignant Tumours (TNM classification) post-surgery [35], type of chemotherapy/radiotherapy, disease site and operation details.

Further baseline measurements will include anthropometry, body composition, dietary intake, physical 


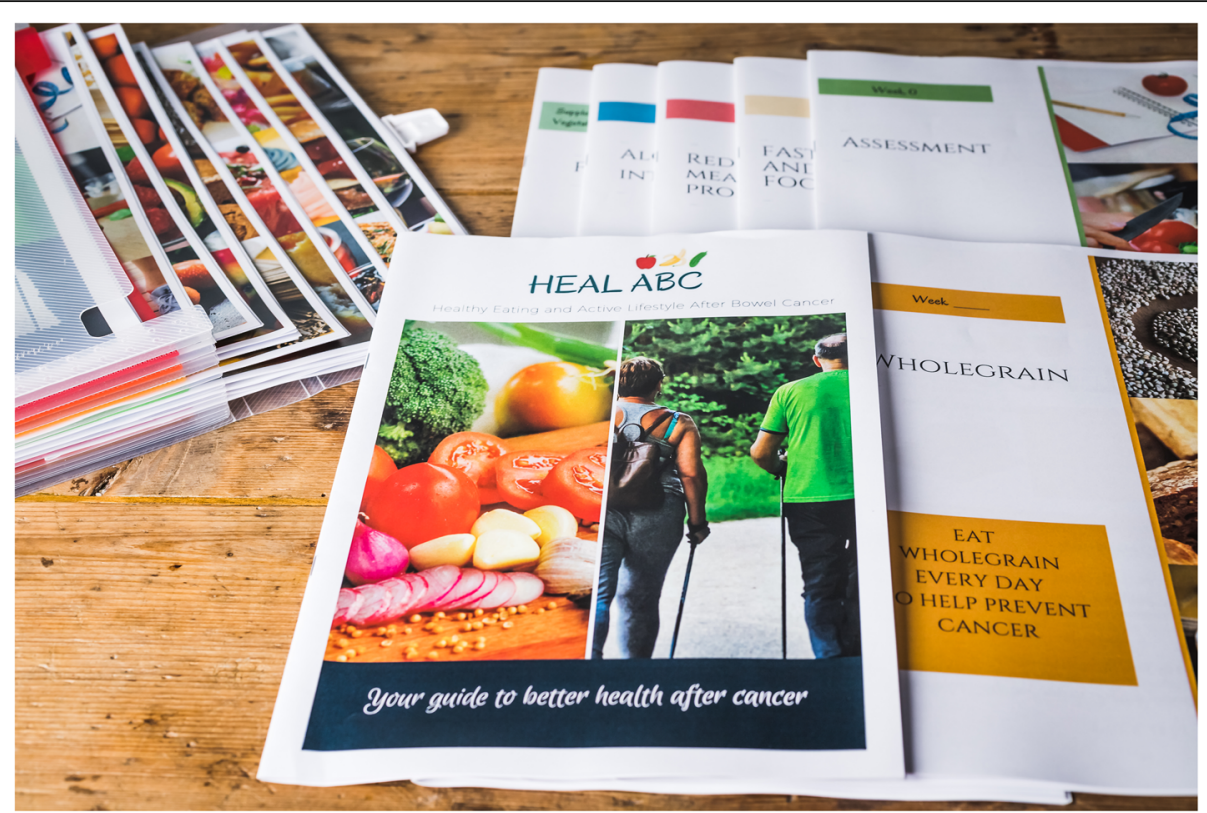

Fig. 2 Healthy Eating and Active Lifestyle After Bowel Cancer-HEAL ABC resources

activity, quality of life, behaviour change assessment and blood tests.

\section{Anthropometry and body composition}

Standard operating procedures will be used to ensure consistency of the measurements. Height will be measured using a stadiometer and records rounded to the nearest centimetre $(\mathrm{cm})$ (Harpenden pocket stadiometer Practical Metrology, Sussex, UK). Body weight will be recorded to the nearest $0.1 \mathrm{~kg}$. Body composition will be measured using bioelectrical impedance analysis (DC-430 MA, Tanita Europe BV, the Netherlands) to assess fat mass and fat-free mass. We will collect copies of computer tomography (CT) scans for participants taken at the closest date to our assessment. The CT scans will be analysed using Slice-o-Matic (Tomovision 5.0, Canada) and Image J (ImageJ, US National Institutes of Health, Bethesda, MA, USA) software. Single axial images at the level of the third lumbar vertebrae will be used to measure total skeletal muscle and total fat mass at the cross-sectional area. Hounsfield units (HU) threshold will be set at -190 to -30 for subcutaneous fat, -150 to -50 for visceral fat, -190 to -30 for intramuscular fat and -29 to 150 for skeletal muscle. The skeletal muscle area will be normalised for stature by

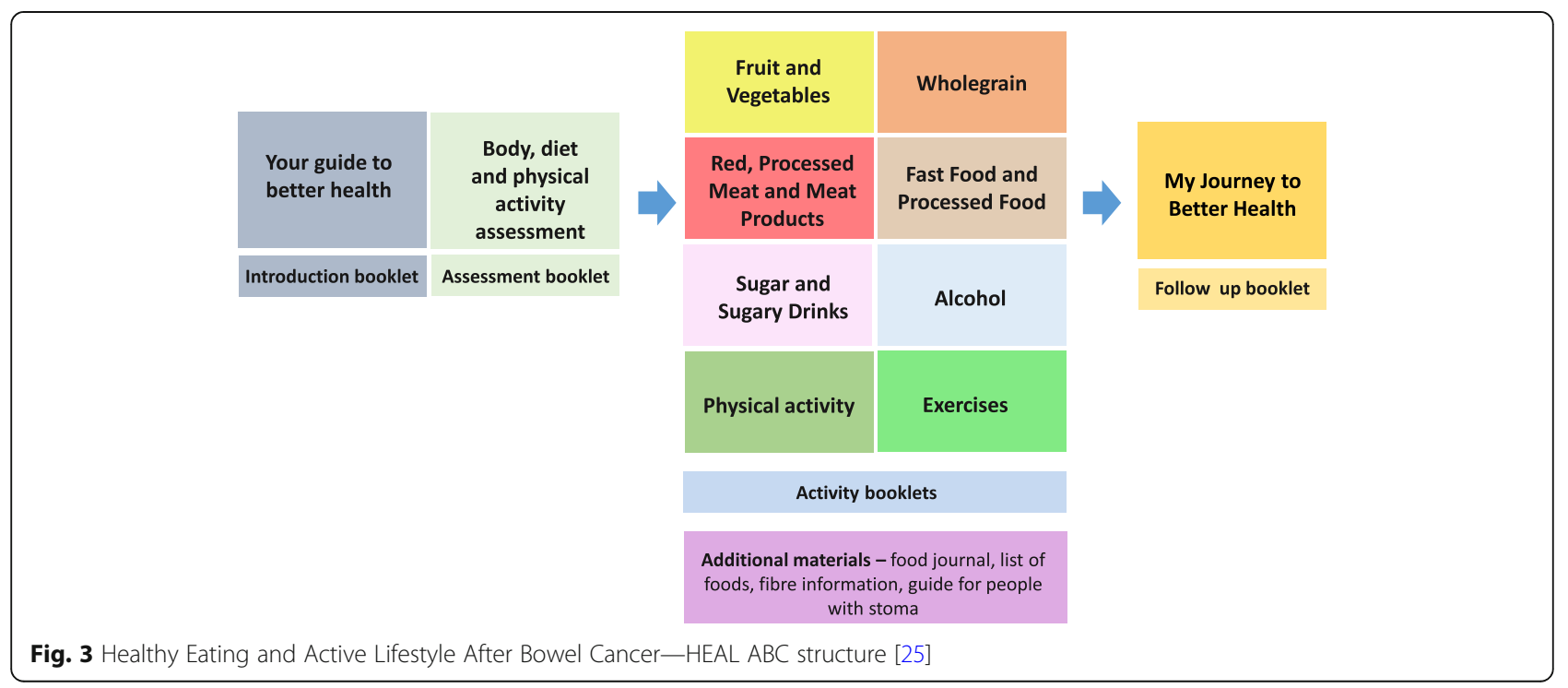


Table 2 Content, strategies and behavioural targets of the Healthy Eating and Active Lifestyle After Bowel Cancer programme

\begin{tabular}{|c|c|c|}
\hline Target & Task & Source \\
\hline Increase awareness of the need to change & Assessment of body, diet and physical activity & Assessment booklet \\
\hline $\begin{array}{l}\text { Understanding benefits of healthy eating habits } \\
\text { and activity lifestyle }\end{array}$ & Information about healthy recommendations & All booklets \\
\hline $\begin{array}{l}\text { Learning about new skills on healthy eating } \\
\text { and active lifestyle }\end{array}$ & $\begin{array}{l}\text { Learning about healthy options, cooking and } \\
\text { shopping tips, understanding portion sizes, } \\
\text { choosing healthier alternatives/adding activities } \\
\text { to daily routines }\end{array}$ & $\begin{array}{l}\text { All diet-related booklets/ } \\
\text { physical activity booklet }\end{array}$ \\
\hline $\begin{array}{l}\text { Exploring current habits and identifying where } \\
\text { the change can be made }\end{array}$ & $\begin{array}{l}\text { Targeted questions on specific dietary } \\
\text { habits/physical activity }\end{array}$ & $\begin{array}{l}\text { All diet-related booklets/ } \\
\text { physical activity booklet }\end{array}$ \\
\hline Selections of specific goal(s) & Action plan & All booklets \\
\hline Creating detailed plan how to achieve selected goal & Action plan & All booklets \\
\hline $\begin{array}{l}\text { Understanding own motivation, risks, barriers, coping } \\
\text { strategies and readiness to change }\end{array}$ & Get ready for your action section & All booklets \\
\hline Calendar with notes to record & Make your notes section & All booklets \\
\hline Review of the goal and action & Review plan & All booklets \\
\hline $\begin{array}{l}\text { Instruction to start new booklet, follow-up with } \\
\text { participants progress, encouragement and support }\end{array}$ & $\begin{array}{l}\text { Supportive calls every } 2 \text { weeks during intervention } \\
\text { and once a month during follow up }\end{array}$ & Telephone calls \\
\hline $\begin{array}{l}\text { Maintenance of new behaviour, encouragement to } \\
\text { start new changes }\end{array}$ & $\begin{array}{l}\text { Calendar for } 12 \text { weeks to track progress and } \\
\text { continue with changes, opportunity to plan } \\
\text { and track new goals }\end{array}$ & $\begin{array}{l}\text { My journey to better } \\
\text { health booklet }\end{array}$ \\
\hline
\end{tabular}

calculating the skeletal muscle index. Muscle mass and fat mass will be calculated using standard equations [36].

\section{Dietary assessment}

Diet will be assessed using a 3-day food diary and electronic dietary recall. Participants will complete a food diary prospectively during the day and enter all foods and drinks consumed into an online system for dietary assessment, INTAKE24 [37], at the end of each day. INTAKE24 is a self-completed online 24-h dietary recall compliant with the general data protection regulation (2018). To complete the dietary recall, participants will be assigned a specific number, which they receive by email. This will serve as a log enabling access to the online dietary record. Participants will be instructed how to complete a food diary and INTAKE24 recall by the researcher, who is a qualified nutritionist. Data collected will be used to assess energy and nutrient consumption, as well as, frequency of fruit and vegetables, red meat, processed meat, fast food, sugary drinks, sweets, and

Table 3 Health Action Process Approach (HAPA) constructs mapped within the Healthy Eating and Active Lifestyle After Bowel programme

\begin{tabular}{|c|c|c|}
\hline Construct & Implementation in HEAL ABC programme & Construct's description \\
\hline Action self-efficacy & $\begin{array}{l}\text { Get ready page in the booklet-how confident } \\
\text { are you about making this change? }\end{array}$ & $\begin{array}{l}\text { Participants believe in their own ability to improve } \\
\text { their diet and to become more active. }\end{array}$ \\
\hline Outcome expectancies & $\begin{array}{l}\text { Get ready page in the booklet-why do you } \\
\text { want to make this change? }\end{array}$ & $\begin{array}{l}\text { Participants believe they will benefit from changing } \\
\text { their behaviour and achieve positive outcomes when } \\
\text { taking part in the HEAL ABC programme. }\end{array}$ \\
\hline Risk perception & $\begin{array}{l}\text { Get ready page in the booklet-why do you } \\
\text { want to make this change? }\end{array}$ & $\begin{array}{l}\text { Participants believe there will be negative consequences } \\
\text { if they do not change their dietary habits and activity level }\end{array}$ \\
\hline Action planning & $\begin{array}{l}\text { Action plan page in the booklet_-creating a } \\
\text { specific action plan }\end{array}$ & $\begin{array}{l}\text { Participants are supported to identify opportunities to } \\
\text { incorporate new eating habit(s) and activity(s) into their } \\
\text { everyday lives. }\end{array}$ \\
\hline Coping planning & $\begin{array}{l}\text { Get ready page in the booklet_-if things do } \\
\text { not go as you plan, what steps will you take to } \\
\text { make sure you stick to your plan? }\end{array}$ & $\begin{array}{l}\text { Participants are supported to identify barriers and make } \\
\text { plans to address them. }\end{array}$ \\
\hline Coping self-efficacy & Motivational interviewing during the phone calls & $\begin{array}{l}\text { Participants believe in their capacity to continue with a } \\
\text { new behaviour even when barriers arise. }\end{array}$ \\
\hline Recovery self-efficacy & Motivational interviewing during the phone calls & $\begin{array}{l}\text { Participants believe they can return to their new behaviour } \\
\text { even when they disengaged with their new activities for } \\
\text { a long period. }\end{array}$ \\
\hline
\end{tabular}


Table 4 Schedule for measurement, testing and assessment at baseline and follow-up assessment

\begin{tabular}{|c|c|c|c|c|c|}
\hline Measure/assessment & Method of assessment & Prior baseline & Baseline & $\begin{array}{l}\text { Post intervention } \\
3 \text { months }\end{array}$ & $\begin{array}{l}\text { Follow-up } \\
6 \text { months }\end{array}$ \\
\hline Enrolment & - & $\checkmark$ & $x$ & $x$ & $x$ \\
\hline Eligibility screen & - & $\checkmark$ & $x$ & $x$ & $x$ \\
\hline Informed consent & - & $\checkmark$ & $x$ & $x$ & $x$ \\
\hline Allocation & - & $x$ & $\checkmark$ & $x$ & $x$ \\
\hline Participants' characteristics & Sociodemographic questionnaire & $x$ & $\checkmark$ & $x$ & $x$ \\
\hline Patients' medical history & Medical records & $x$ & $\checkmark$ & $x$ & $x$ \\
\hline Anthropometry & Scale, tape measure, stadiometer & $x$ & $\checkmark$ & $\checkmark$ & $\checkmark$ \\
\hline Body composition & BIA, CT scans analysis & $x$ & $\checkmark$ & $\checkmark$ & $\checkmark$ \\
\hline Dietary assessment & 3-day food diary, 24 dietary recall & $x$ & $\checkmark$ & $\checkmark$ & $\checkmark$ \\
\hline Physical activity level & GPAQ Questionnaire & $x$ & $\checkmark$ & $\checkmark$ & $\checkmark$ \\
\hline Step count & Pedometer & $x$ & $\checkmark$ & $\checkmark$ & $\checkmark$ \\
\hline Behaviour/motivation & HAPA questionnaire & $x$ & $\checkmark$ & $\checkmark$ & $\checkmark$ \\
\hline Participant's experience & In-depth interviews & $x$ & $x$ & $\checkmark$ & $\checkmark$ \\
\hline Quality of life & SF-12 questionnaire & $x$ & $\checkmark$ & $\checkmark$ & $\checkmark$ \\
\hline Participants' contact with healthcare services & Healthcare Resource Use Questionnaire & $x$ & $x$ & $x$ & $\checkmark$ \\
\hline Morbidities, mortality & Medical records & $x$ & $x$ & $x$ & $\checkmark$ \\
\hline
\end{tabular}

BIA bio-impedance analysis, CT computer tomography, GPAQ Global Physical Activity Questionnaire, SF-12 Short form 12 quality of life

alcohol. This method of food frequency assessment will replace a standard food frequency questionnaire, which is subjected to reporting error due to the inaccuracy of absolute nutrient values, variation of nutrient values depending on questionnaire length and structure and lack of details recorded about food consumed [38, 39]. Further advantages of combining food diary and electronic recall relate to participant's age and memory capacity, as the average age of CRC survivors is above 65 years. In addition, a Diet Quality Index will be calculated based on data collected [40].

\section{Physical activity level}

The Global Physical Activity Questionnaire (GPAQ) will be used to assess participant's level of physical activity [41]. A validated pedometer will be used [42, 43] to measures daily steps for a week at each time point. Participants will be instructed to wear the pedometer during the day clipped to their waistband on either the left or right hip.

\section{Quality of life}

Health-related quality of life will be assessed using the SF-12 questionnaire [44], selected for its validity, generalisability and simplicity $[45,46]$.

\section{Behaviour change}

Behaviour change will be assessed using a behaviour change questionnaire, using questions derived from the HAPA. This questionnaire was developed to explore changes in different HAPA constructs (aspects related to participant's behaviour). The HAPA questionnaire has been previously used to investigate changes in HAPA constructs in lifestyle interventions [47-49].

\section{Biochemistry and haematology}

Blood test results of routinely collected inflammatory markers (C-reactive protein, leukocytes level, albumin, haemoglobin) will be collected from patient's medical records [50].

\section{Post-intervention assessment at 3 months}

At 3 months, all baseline measurements will be repeated. In addition, a subset of 12 to 15 participants in the intervention group will be interviewed using qualitative interviews. The interviews will aim to gain an insight into participants' experience of being in the study, using HEAL ABC resources, and will explore motivations, barriers and facilitators regarding adherence to the intervention. A subset of 12 to 15 participants in the control group will also be interviewed about the experience in the study, their level of motivation and action taken towards a healthier lifestyle.

\section{Follow-up assessment at 6 months}

At 6 months, all baseline measurements will be repeated, and qualitative interviews will be performed again with the same subset of participants. Additionally, cancer recurrences, morbidities and survival will be collected 
from patients' medical records and health resource questionnaire provided.

\section{Healthcare Resource Use Questionnaire}

A health economics questionnaire will be used to find out about patient's contact with primary and secondary healthcare services. The questionnaire was developed by a health economist for the European Union funded project "PreventIT" [51].

\section{Qualitative interviews at 3 and 6 months}

We will aim to recruit participants for interviews until data saturation is achieved and we anticipate this will be between 12 and 15 participants [52]. Overall, this will provide 24-30 interviews in total, and 12-15 interviews at each time point is considered to be sufficient to reach data saturation as recommended by Guest et al. [53]. Participants will be selected at baseline, as the first 12 to 15 who agree to be interviewed. This will allow an early evaluation of participants' experience of the study. A topic guide developed for the study will be used to conduct the interviews. The guide will cover topics such as experience of randomisation, intervention, HEAL ABC resources and data collection. It will also discuss motivation, barriers and facilitators for following the HEAL $A B C$ intervention. The topic guide will be continually reviewed throughout the interview process to ensure it covers any emerging topics of interest. Interviews will be audio-recorded using an encrypted audio recorder and will be fully transcribed verbatim.

\section{Outcomes}

Outcome related to feasibility will be assessed by adherence to WCRF/AICR guidelines, recruitment rates, retention rates, data completion rates and loss to follow up. Adherence to intervention will be assessed as adherence to the WCRF/AICR guidelines by using a scoring system for nutrition and physical activity guideline adherence developed by McCullough and colleagues [54, 55]. We will also assess number of goals set and number of changes implemented in everyday life during the 3-month intervention. Recruitment rates will be assessed as a cumulative recruitment against target rate each month and retention rates calculated as the number of participants who completed the study divided by the number of participants randomised. Acceptability of the intervention will be explored qualitatively through interviews with a subset of the study participants. Data completion rates will be judged as percentage of missing data and completeness of data for all outcome measures at all the time points. Changes in means and standard deviation will be compared to allow for the sample size calculation for a future trial.
Other outcomes include assessing the practicality of data collection for dietary intake, physical activity levels, behaviour change in relation to diet and physical activity and determining effect sizes for these outcomes. Interviews will be performed to explore participants' experience, motivation, barriers and facilitators to use HEAL $\mathrm{ABC}$ resources and follow the intervention.

In the future, a fully powered RCT will test the efficacy of the intervention alongside outcomes collected in the feasibility trial.

\section{Sample size}

We plan to complete the study with 60 participants allowing for up to $15 \%$ drop out over 12 months so will recruit a total of 72 participants. This is based on drop out data identified in a systematic review of the literature [8]. As this study does not aim to test a hypothesis, we follow recommendations for feasibility studies by Lancaster et al. [56].

\section{Randomisation}

Participants will be randomised into control and intervention groups using the sealedenvelope.com [57] block randomisation. The randomisation will be stratified for hospital site and cancer site (colon or rectum). An independent person outside of the research team will generate the allocation sequence and assign participants into their groups. Participants cannot be completely blinded to the intervention but effort was taken to blind differences between HEAL and HEALTH group for participants through the provision of written materials and following the same assessment. The researcher will not be blinded to the intervention and outcomes.

\section{Statistical analysis}

Quantitative data will be analysed using descriptive statistics displayed with $95 \%$ confidence intervals. Changes in outcomes between the intervention arm and control, estimate parameters using means and standard deviations will be descriptively compared and will inform a sample size calculation for a full RCT. All quantitative data will be analysed in STATA 15 (StataCorp, TX: StataCorp LLC) [58].

Qualitative interview transcripts will be managed using NVivo 12 software (QSR International Pty Ltd., Doncaster, VIC, Australia) and analysed using the five stages of framework analysis [59]: familiarisation, developing a thematic framework, indexing, charting and mapping and interpretation. During the first stage (familiarisation) the researcher will become immersed in the data, by reading and re-reading the transcripts. Next, a thematic framework will be developed. After this, transcripts will be indexed (coded) line by line using the thematic framework but remaining open to new themes that 
emerge. Next, the data will be entered into a chart, so that coded extracts can be attributed to individual participants. Finally, participants' views will be compared and contrasted, and the data presented schematically (mapping). Contrasting explanations will be explored.

\section{Discussion}

Cancer survivorship research is a relatively new research area but has been identified as addressing the important gap in cancer research [7]. Other researchers have been pioneers in cancer survivorship research emphasising the promotion of long-term health for cancer survivors [60], developed an evidence based interventions primarily for breast cancer survivors $[61,62]$ and demonstrated positive changes in dietary and other health outcomes in several RCTs [8, 21, 23]. In colorectal cancer, only a few trials have been published to date $[63,64]$, and many gaps exist within the evidence base [8]; therefore, more research is required in this cancer population.

In recent years, a few study protocols have been published on lifestyle interventions for people after cancer. The Advancing Survival after Cancer Outcomes Trial (ASCOT) study has been designed for all cancer survivors [65]. However, one could argue that there are fundamental differences in diet and physical activity requirements between people with different cancers. It is therefore difficult to apply general lifestyle interventions equally to those after breast cancer and those after CRC, due to specific consequences of treatment including the presence of a stoma. Thus, more tailored interventions and resources addressing needs of specific survivor populations seem necessary. Furthermore, the Norwegian dietary guidelines and colorectal cancer survival (CRCNORDIET) protocol has been designed as a very opportunistic intervention that offers participants healthy food delivery, cooking classes, individual consultations with a dietitian, access to a training studio and other benefits [66]. This trial with a 14-year follow-up period has a great potential to demonstrate that healthy eating and active lifestyles have a positive impact on health outcomes of people after CRC and their overall survival. However, such an intervention is very unlikely to be accepted by public health policy commissioners and translated into patient care pathways due to high levels of resources required to sustain and unrealistic demands on service providers within healthcare.

The proposed RCT aims to evaluate the feasibility of conducting a fully powered trial for the HEAL ABC intervention. This study has been developed from previous research within the area of CRC survivorship including qualitative work $[18,25]$, discrete choice experiment [24] and systematic reviews $[19,63]$. The proposed study attempts to address areas where research is lacking in the evidence base identified by a Cochrane Systematic review on dietary interventions for cancer survivors [8]. It is based on extensive qualitative work with CRC survivors, which is in line with evidence published by other research groups $[17,67-70]$. In conjunction, the intervention has incorporated behaviour change theory and the study aims to test the implementation of this behaviour theory during delivery of the intervention.

\section{Study limitations}

The study is a multicentre feasibility RCT involving hospitals across Greater Manchester and thus the results might not be completely generalisable to the whole of the UK or other countries. The assessment process for most of the study outcomes is based on questionnaires, dietary records and audio recordings. Hence, the research relies heavily on participants' recall and accurate reporting.

\section{Summary}

To date, many trials have focused on the efficacy of the intervention and overlooked important methodological steps in the research design that might impact on adherence to the intervention and behaviour change. If the intervention is not successful in achieving a high level of adherence and participants do not change their behaviour, there is limited potential to observe any differences between the groups for nutritional, clinical and behavioural outcomes. Hence, improvement in design, study resources and conduct of clinical trials are imperative and possibly can improve the efficacy of evaluating lifestyle interventions designed for survivors of cancer.

\section{Supplementary Information}

The online version contains supplementary material available at https://doi. org/10.1186/s40814-020-00721-y.

Additional file 1. Sociodemographic questionnaire.

Additional file 2. SPIRIT checklist.

\begin{abstract}
Abbreviations
BIA: Bio-impedance analysis; CRC: Colorectal cancer; CT: Computer tomography; HAPA: Health Action Process Approach; HEAL ABC: Healthy Eating and Active Lifestyle After Bowel Cancer; GPAQ: Global Physical Activity Questionnaire; MRC: Medical Research Council; RCTs: Randomised controlled trials; SF-12: Short form 12 quality of life questionnaire; WCRF/AICR: World Cancer Research Fund and American Institute of Cancer Research
\end{abstract}

\section{Acknowledgements}

Authors would like to thank to Dr. Elisabeth Boulton for expertise on behaviour change questionnaire development, to Dr. Helen Hawley-Hague and Dr. Fan Yang for advice on health economics and to the PreventIT trial team for permission to use their health economics questionnaire. We would like to thank to Dr. Antonia Marsden for statistical review and to all site principal investigators Prof. Jim Hill, Prof. John McLaughlin and Mr. Ramesh for their support in this trial.

Trial sponsor

This study is sponsored by the University of Manchester. 


\section{Authors' contributions}

JS, SB, AMS and CT contributed to study design and protocol development. $\mathrm{RC}$ provided expertise on behaviour change aspects in the intervention. All authors read and approved the final manuscript.

\section{Funding}

This study is funded by the Research Impact Scholarship Award, provided by the Division of Development and Alumni Relations of the University of Manchester and by National Institute for Health Research (NIHR) as part of Prof. Todd's Senior Investigator award.

\section{Availability of data and materials}

Not applicable.

\section{Ethics approval and consent to participate}

The study was approved by the North West-Greater Manchester South Research Ethics Committee (reference number IRAS ID 273818). The study was registered with the National Institute of Health Clinical Trials (www. ClinicalTrials.gov, identifier NCT04227353). Written informed consent will be obtained from participants enrolled in the HEAL ABC study.

\section{Consent for publication}

Not applicable.

\section{Competing interests}

The authors declare that they have no competing interests.

\section{Author details}

${ }^{1}$ School of Health Sciences, University of Manchester, Oxford Road, Manchester M13 9PL, UK. ${ }^{2}$ Manchester Academic Health Science Centre, Manchester, UK. ${ }^{3}$ Manchester University NHS Foundation Trust, Manchester, UK. ${ }^{4}$ NIHR Applied Research Collaboration Greater Manchester, Manchester, UK. ${ }^{5}$ Department of Psychology, University of Liverpool, Liverpool, UK. ${ }^{6}$ Salford Royal NHS Foundation Trust, Salford, UK.

\section{Received: 19 May 2020 Accepted: 3 November 2020}

\section{Published online: 13 November 2020}

\section{References}

1. Bray F, Ferlay J, Soerjomataram I, Siegel RL, Torre LA, Jemal A. Global cancer statistics 2018: GLOBOCAN estimates of incidence and mortality worldwide for 36 cancers in 185 countries. CA Cancer J Clin. 2018;68(6):394-424.

2. Kinsella KG, Phillips DR. Global aging: the challenge of success. Popul Bull. 2005:60(1):3-40

3. Roser M, Ritchie H. Cancer 2020 [cited 202015 February ]. Available from: https://ourworldindata.org/cancer.

4. National Cance Research Institute. Definitions 2019 [cited 20208 February ]. Available from: https://cancercontrol.cancer.gov/ocs/statistics/index. html\#definition-survivorship.

5. Vergnaud AC, Romaguera D, Peeters PH, van Gils $\mathrm{CH}$, Chan DS, Romieu I, et al. Adherence to the World Cancer Research Fund/American Institute for Cancer Research guidelines and risk of death in Europe: results from the European Prospective Investigation into Nutrition and Cancer cohort study. Am J Clin Nutr. 2013;97(5):1107-20.

6. Schwedhelm C, Boeing H, Hoffmann G, Aleksandrova K, Schwingshackl L. Effect of diet on mortality and cancer recurrence among cancer survivors: a systematic review and meta-analysis of cohort studies. Nutr Rev. 2016; 74(12):737-48.

7. World Cancer Research Fund/American Institute for Cancer Research Continuous Update Project Expert Report. Diet, Nutrition Physical Activity and Cancer: a Global Perpective. 2018 [cited 20196 Jun]. Available from: https://wcrforg/dietandcancer.

8. Burden S, Jones DJ, Sremanakova J, Sowerbutts AM, Lal S, Pilling M, Todd C. Dietary interventions for adult cancer survivors. Cochrane Database Syst Rev. 2019;2019(11):CD011287. https://doi.org/10.1002/14651858.CD011287. pub2. PMID: 31755089; PMCID: PMC6872979.

9. World Cancer Research Fund/American Institute for Cancer Research. Survivors of breast cancer and other cancers 2018 [cited 202018 March]. Available from: https://www.wcrf.org/dietandcancer.
10. Arnold M, Sierra MS, Laversanne M, Soerjomataram I, Jemal A, Bray F. Global patterns and trends in colorectal cancer incidence and mortality. Gut. 2017; 66(4):683-91.

11. Cancer Resarch UK. Bowel cancer statistics [cited 201815 December]. Available from: https://www.cancerresearchuk.org/health-professional/ cancer-statistics/statistics-by-cancer-type/bowel-cancer\#heading-Zero.

12. De Marco M, Janssen-Heijnen M, Van der Heijden L, Coebergh J. Comorbidity and colorectal cancer according to subsite and stage: a population-based study. Eur J Cancer. 2000;36(1):95-9.

13. Denlinger CS, Barsevick AM. The challenges of colorectal cancer survivorship. J Natl Comprehensive Cancer Network. 2009;7(8):883-94.

14. Cooper C, Burden ST, Cheng H, Molassiotis A. Understanding and managing cancer-related weight loss and anorexia: insights from a systematic review of qualitative research. J Cachexia Sarcopenia Muscle. 2015;6(1):99-111.

15. Duineveld LA, van Asselt KM, Bemelman WA, Smits AB, Tanis PJ, van Weert $H C$, et al. Symptomatic and asymptomatic colon cancer recurrence: a multicenter cohort study. Ann Fam Med. 2016;14(3):215-20.

16. Evans HS, Moller H, Robinson D, Lewis CM, Bell CM, Hodgson SV. The risk of subsequent primary cancers after colorectal cancer in southeast England. Gut. 2002;50(5):647-52.

17. Balhareth A, Aldossary MY, McNamara D. Impact of physical activity and diet on colorectal cancer survivors' quality of life: a systematic review. World J Surg Oncol. 2019;17(1):153.

18. Burden ST, Stamataki Z, Hill J, Molasiotis A, Todd C. An exploration of food and the lived experience of individuals after treatment for colorectal cancer using a phenomenological approach. Journal of Human Nutrition and Dietetics. 2016;29(2):137-45.

19. Burden S, Sremanakova J, Jones D, Todd C. Dietary interventions for cancer survivors. Proc Nutr Soc. 2018:1-11. https://doi.org/10.1017/ S0029665118002690.

20. Craig P, Dieppe P, Macintyre S, Michie S, Nazareth I, Petticrew M, et al. Developing and evaluating complex interventions: the new Medical Research Council guidance. BMJ. 2008;337:a1655.

21. Demark-Wahnefried W, Clipp EC, Lipkus IM, Lobach D, Snyder DC, Sloane R, et al. Main outcomes of the FRESH START trial: a sequentially tailored, diet and exercise mailed print intervention among breast and prostate cancer survivors. J Clin Oncol. 2007;25(19):2709-18.

22. Pierce JP, Natarajan L, Caan BJ, Parker BA, Greenberg ER, Flatt SW, et al. Influence of a diet very high in vegetables, fruit, and fiber and low in fat on prognosis following treatment for breast cancer: the Women's Healthy Eating and Living (WHEL) randomized trial. Jama. 2007;298(3):289-98.

23. Greenlee H, Gaffney AO, Aycinena AC, Koch P, Contento I, Karmally W, et al. ¡Cocinar Para Su Salud!: randomized controlled trial of a culturally based dietary intervention among Hispanic breast cancer survivors. J Acad Nutr Diet. 2015;115(5):709-23 e3.

24. Wright SJ, Gibson D, Eden M, Lal S, Todd C, Ness A, et al. What are colorectal cancer survivors' preferences for dietary advice? A best-worst discrete choice experiment. J Cancer Surviv. 2017;11(6):782-90.

25. Sremanakova J, Jones D, Cooke R, Burden S. Exploring views of healthcare professionals, researchers, and people living with and beyond colorectal cancer on a healthy-eating and active lifestyle resource. Nutrients. 2019; 11(10):2482. https://doi.org/10.3390/nu11102482. PMID: 31623177; PMCID: PMC6835229.

26. Schwarzer R. The Health Action Process Approach (HAPA) [cited 201910 December]. Available from: http://www.hapa-model.de/.

27. Eldridge SM, Chan CL, Campbell MJ, Bond CM, Hopewell S, Thabane L, et al. CONSORT 2010 statement: extension to randomised pilot and feasibility trials. Pilot Feasibility Stud. 2016;2:64.

28. Chan AW, Tetzlaff JM, Altman DG, Laupacis A, Gotzsche PC, Krleza-Jeric K, et al. SPIRIT 2013 statement: defining standard protocol items for clinical trials. Ann Intern Med. 2013;158(3):200-7.

29. World Cancer Research Fund/American Institute for Cancer Research. Continuous update project expert report 2018. Diet, nutrition, physical activity and colorectal cancer 2018 [cited 201919 March]. Available from: https://www.wcrf.org/sites/default/files/Colorectal-cancer-report.pdf.

30. Weber M, Belala N, Clemson L, Boulton E, Hawley-Hague H, Becker C, et al. Feasibility and effectiveness of intervention programmes integrating functional exercise into daily life of older adults: a systematic review. Gerontology. 2018;64(2):172-87.

31. Boulton E, Hawley-Hague H, French DP, Mellone S, Zacchi A, Clemson L, et al. Implementing behaviour change theory and techniques to increase 
physical activity and prevent functional decline among adults aged 61-70: The PreventIT project. Prog Cardiovasc Dis. 2019;62(2):147-56.

32. Schunk DH. Goal setting and self-efficacy during self-regulated learning. Educ Psychol. 1990;25(1):71-86.

33. Miller WR, Rollnick S. Applications of motivational interviewing. Motivational interviewing: Helping people change (3rd edition). Washington: Guilford Press; 2013. https://psycnet.apa.org/record/2012-17300-000.

34. Moyers TB, Rowell LN, Manuel JK, Ernst D, Houck JM. The Motivational Interviewing Treatment Integrity Code (MITI 4): rationale, preliminary reliability and validity. J Subst Abuse Treat. 2016;65:36-42.

35. Sobin LH, Hermanek P, Hutter RV. TNM classification of malignant tumors. A comparison between the new (1987) and the old editions. Cancer. 1988; 61(11):2310-4

36. Mourtzakis M, Prado CM, Lieffers JR, Reiman T, McCargar $\sqcup$, Baracos VE. A practical and precise approach to quantification of body composition in cancer patients using computed tomography images acquired during routine care. Appl Physiol Nutr Metab. 2008:33(5):997-1006.

37. Dietary Assessment Ltd. My Food 24 [cited 201815 November]. Available from: https://www.myfood24.org/web/.

38. Briefel RR, Flegal KM, Winn DM, Loria CM, Johnson CL, Sempos CT. Assessing the nation's diet: limitations of the food frequency questionnaire. J Am Diet Assoc. 1992;92(8):959-62.

39. Shim JS, Oh K, Kim HC. Dietary assessment methods in epidemiologic studies. Epidemiol Health. 2014;36:e2014009.

40. Patterson RE, Haines PS, Popkin BM. Diet quality index: capturing a multidimensional behavior. J Am Diet Assoc. 1994;94(1):57-64.

41. Organisation W. H. Global Physical Activity Questionnaire (GPAQ) analysis guide [cited 201820 November]. Available from: http://www.who.int/ncds/ surveillance/steps/resources/GPAQ_Analysis_Guide.pdf.

42. Schneider PL, Crouter S, Bassett DR. Pedometer measures of free-living physical activity: comparison of 13 models. Med Sci Sports Exerc. 2004;36(2): 331-5.

43. Schneider PL, Crouter SE, Lukajic O, Bassett DR Jr. Accuracy and reliability of 10 pedometers for measuring steps over a 400-m walk. Med Sci Sports Exerc. 2003;35(10):1779-84.

44. Optum Inc. SF-12v2 Health Survey [cited 201810 December]. Available from: https://campaign.optum.com/content/optum/en/optum-outcomes/ what-we-do/health-surveys/sf-12v2-health-survey.html.

45. Ware J Jr, Kosinski M, Keller SD. A 12-Item Short-Form Health Survey: construction of scales and preliminary tests of reliability and validity. Med Care. 1996;34(3):220-33.

46. Jenkinson $C$, Layte $R$, Jenkinson $D$, Lawrence $K$, Petersen $S$, Paice $C$, et al. A shorter form health survey: can the SF-12 replicate results from the SF-36 in longitudinal studies? J Public Health Med. 1997;19(2):179-86.

47. Rohani H, Eslami AA, Ghaderi A, Bidkhori M, Raei M. Development and psychometric evaluation of a health action process approach inventory for healthful diet among type 2 diabetes patients. Int J Prev Med. 2016;7:69.

48. Radtke T, Kaklamanou D, Scholz U, Hornung R, Armitage CJ. Are diet-specific compensatory health beliefs predictive of dieting intentions and behaviour? Appetite. 2014;76:36-43.

49. Zhou G, Gan Y, Knoll N, Schwarzer R. Proactive coping moderates the dietary intention-planning-behavior path. Appetite. 2013;70:127-33.

50. Ghuman S, Van Hemelrijck M, Garmo H, Holmberg L, Malmstrom H, Lambe $M$, et al. Serum inflammatory markers and colorectal cancer risk and survival. Br J Cancer. 2017;116(10):1358-65.

51. Taraldsen K, Mikolaizak AS, Maier AB, Boulton E, Aminian K, van Ancum J, et al. Protocol for the PreventIT feasibility randomised controlled trial of a lifestyle-integrated exercise intervention in young older adults. BMJ Open. 2019;9(3):e023526

52. Saunders B, Sim J, Kingstone T, Baker S, Waterfield J, Bartlam B, et al. Saturation in qualitative research: exploring its conceptualization and operationalization. Qual Quant. 2018;52(4):1893-907.

53. Guest G, Bunce A, Johnson L. How many interviews are enough?: an experiment with data saturation and variability. Field Methods. 2006;18(1): 59-82.

54. McCullough ML, Patel AV, Kushi LH, Patel R, Willett WC, Doyle C, et al. Following cancer prevention guidelines reduces risk of cancer, cardiovascular disease, and all-cause mortality. Cancer Epidemiol Biomarkers Prev. 2011;20(6):1089-97.

55. Park SH, Knobf MT, Kerstetter J, Jeon S. Adherence to American Cancer Society Guidelines on nutrition and physical activity in female cancer survivors: results from a randomized controlled trial (Yale Fitness Intervention Trial). Cancer Nurs. 2019;42(3):242-50.

56. Lancaster GA, Dodd S, Williamson PR. Design and analysis of pilot studies: recommendations for good practice. J Eval Clin Pract. 2004;10(2):307-12.

57. Sealed Envelope. Simple randomisation service [cited 201810 December]. Available from: https://www.sealedenvelope.com/simple-randomiser/v1/ trials/together-trial.

58. StataCorp. Stata Statistical Software: Release 15. College Station: TX: StataCorp LLC; 2017.

59. Ritchie J, Lewis J. Qualitative Research Practice: A Guide for Social Science Students and Researchers. London: Sage Publications; 2003.

60. Demark-Wahnefried W, Aziz NM, Rowland JH, Pinto BM. Riding the crest of the teachable moment: promoting long-term health after the diagnosis of cancer. J Clin Oncol. 2005;23(24):5814-30.

61. Demark-Wahnefried W, Clipp EC, McBride C, Lobach DF, Lipkus I, Peterson B, et al. Design of FRESH START: a randomized trial of exercise and diet among cancer survivors. Med Sci Sports Exerc. 2003;35(3):415-24.

62. Aycinena AC, Jennings KA, Gaffney AO, Koch PA, Contento IR, Gonzalez M et al. ¡Cocinar Para Su Salud! Development of a culturally based nutrition education curriculum for Hispanic breast cancer survivors using a theorydriven procedural model. Health Educ Behav. 2017;44(1):13-22.

63. Aubrey V, Hon Y, Shaw C, Burden S. Healthy eating interventions in adults living with and beyond colorectal cancer: a systematic reivew. J Hum Nutr Dietetics. 2018;32(4):501-11.

64. Moug SJ, Bryce A, Mutrie N, Anderson AS. Lifestyle interventions are feasible in patients with colorectal cancer with potential short-term health benefits: a systematic review. Int J Colorectal Dis. 2017;32(6):765-75.

65. Beeken RJ, Croker H, Heinrich M, Smith L, Williams K, Hackshaw A, et al. Study protocol for a randomised controlled trial of brief, habit-based, lifestyle advice for cancer survivors: exploring behavioural outcomes for the Advancing Survivorship Cancer Outcomes Trial (ASCOT). BMJ Open. 2016; 6(11):e011646.

66. Henriksen HB, Raeder H, Bohn SK, Paur I, Kvaerner AS, Billington SA, et al. The Norwegian dietary guidelines and colorectal cancer survival (CRCNORDIET) study: a food-based multicentre randomized controlled trial. BMC Cancer. 2017;17(1):83.

67. Gordon LG, Patrao T, Kularatna S, Hawkes AL. A telephone-delivered multiple health behaviour change intervention for colorectal cancer survivors: making the case for cost-effective healthcare. Eur J Cancer Care. 2015;24(6):854-61.

68. Grimmett C, Simon A, Lawson V, Wardle J. Diet and physical activity intervention in colorectal cancer survivors: a feasibility study. Eur J Oncol Nurs. 2015;19(1):1-6.

69. Dennis DL, Waring JL, Payeur N, Cosby C, Daudt HM. Making lifestyle changes after colorectal cancer: insights for program development. Curr Oncol. 2013:20(6):e493-511.

70. Palmer NR, Bartholomew LK, McCurdy SA, Basen-Engquist KM, Naik AD. Transitioning from active treatment: colorectal cancer survivors' health promotion goals. Palliat Support Care. 2013;11(2):101-9.

\section{Publisher's Note}

Springer Nature remains neutral with regard to jurisdictional claims in published maps and institutional affiliations.

Ready to submit your research? Choose BMC and benefit from:

- fast, convenient online submission

- thorough peer review by experienced researchers in your field

- rapid publication on acceptance

- support for research data, including large and complex data types

- gold Open Access which fosters wider collaboration and increased citations

- maximum visibility for your research: over $100 \mathrm{M}$ website views per year

At $\mathrm{BMC}$, research is always in progress.

Learn more biomedcentral.com/submission 